\title{
Standard Normal Fetal Lung Volume by MRI Measurement
}

\author{
Sepideh Sefidbakht ${ }^{1}$, Amin Dehdashtian ${ }^{1,{ }^{*}}$, Fereshte Bagheri ${ }^{1}$, Neda Rahimirad ${ }^{2}$, Pedram Keshavarz $^{1}$ \\ and Bijan Bijan ${ }^{3}$
}

\author{
${ }^{1}$ Department of Radiology, Medical Imaging Research Center, Shiraz University of Medical Sciences, Shiraz, Iran \\ ${ }^{2}$ Perinatology Research Center, Shiraz University of Medical Sciences, Shiraz, Iran \\ ${ }^{3}$ Sutter Imaging (SMG), University of California Davis Medical Center, Sacramento, USA \\ "Corresponding author: Department of Radiology, Medical Imaging Research Center, Shiraz University of Medical Sciences, Shiraz, Iran. Tel: +98,9126952080, Email: \\ amindn66@gmail.com
}

Received 2019 September 05; Revised 2020 February 05; Accepted 2020 February 09.

\begin{abstract}
Background: Pulmonary hypoplasia is a significant decrease in lung volume by any cause in comparison to the normal volume for gestational age.

Objectives: To evaluate the application of prenatal magnetic resonance imaging in order to predict pulmonary hypoplasia, measurement of fetal lung volume (FLV) was aimed to establish a reference data in normal fetuses.

Patients and Methods: Three hundred forty two fetuses with abnormal ultrasound findings underwent fast spin-echo T2-weighted MR imaging at a single tertiary care hospital (Shahid Faghihi Hospital, Shiraz, Iran). Data of 241 fetuses at 18 - 36 weeks' gestation without thoracic malformations were obtained for a FLV normative curve. To acquire a best-fit formula for the mean total fetal lung volume based on each gestational week with 95\% confidence interval (CI), we used the regression model applied by Rypens et al. This resulted in a formula calculating the expected fetal lung volume based on gestational age. A one-sample $t$-test was also carried out to compare the mean total fetal lung volume at each gestational week with the expected mean total fetal lung volume predicted by the formula by Rypens et al., Meyers et al., and Osada et al.

Results: Normal FLV increased with gestational age as the spread of values. The expected fetal lung volume was derived from the following formula: Fetal lung volume $(\mathrm{mL})=0.002 \times\left(\right.$ gestational age $\left.[\mathrm{GA}]^{2.913}\right)$, in which GA is gestational weeks. FLV in our population had a more consistent correlation with Japanese fetuses than European or American fetuses.

Conclusion: In fetuses with normal lungs, FLV distribution against gestational age is simply measured prenatally with MR imaging. A single universal formula might not be suitable for fetuses worldwide. In our region, acquired data were more consistent with Asian normal values.
\end{abstract}

Keywords: Lung Volume Measurement, Fetal, MRI, Pulmonary Hypoplasia

\section{Background}

Pulmonary hypoplasia is a significant decrease in lung volume in comparison to the normal volume for gestational age (1). Depending on the severity of the condition it could lead to impaired respiratory function, postnatal intensive care or incompatibility with life. Pulmonary hypoplasia can be caused by various etiologies such as oligohydramnios, congenital diaphragmatic hernia, pulmonary masses, chest wall deformities, and hydrothorax (2). For some of these conditions, prenatal intervention is available based on the degree of pulmonary hypoplasia. In all these conditions, prognosis and proper management depends on the volume of remaining normal lung tissue. Thus, precise prenatal diagnosis and quantification of pulmonary hypoplasia is particularly crucial.
Three-dimensional ultrasound and magnetic resonance imaging (MRI) are the two well-established modalities that are clinically used to measure fetal lung volume. While MRI is not universally available, ultrasound is generally limited by poor acoustic distinction of the lung tissue from adjacent structures $(3,4)$. Ultrasound might also be technically challenging or impossible to perform with diagnostic quality in patients with oligohydramnios or large abdomen.

Technical advances in MRI including fast pulse sequences (5), especially single-shot fast spin echo imaging (6-8) has made MR imaging of the moving fetus possible. These sequences are less motion sensitive than older sequences and could lead to detailed anatomical evaluation including lung volume measurement. The possibility for pulmonary hypoplasia could be evaluated by compar- 
ing the fetal lung volume with a normal range for gestational age. Multiple studies have tried to establish normal lung volumes for various gestational ages (9-13). However, the results are not uniform between studies; with variations most noticeable between different populations (14, 15). Moreover, due to paucity of data on early gestation and widespread second trimester screening, there is an increasing need for establishing normal values for early midtrimester lung volume.

\section{Objectives}

In the present study, we aimed to measure the volume of the fetal lung using MR imaging to establish a reference data in our population. To our knowledge no such study has been performed in the Middle East.

\section{Patients and Methods}

\subsection{Patient Population}

Between April 2014 and March 2017, 342 pregnant women were referred to a single tertiary care hospital (Shahid Faghihi Hospital, Shiraz, Iran) for fetal MRI. Suspicion for central nervous system diseases such as ventriculomegaly and morbidly adherent placenta were the most frequent indications for referral. Other morphologic abnormalities such as renal disease, echogenic bowel, dilated stomach, abdominal mass, intrauterine growth retardation (IUGR), inadequate amniotic fluid, hydropes, and polydactyly were the remaining causes of referral. Among them, some were excluded due to intervening factors (which are shown in Figure 1) and the total number of 241 cases, aged $30.5 \pm 5.51$ years (range: 18 - 45) with a gestational age of $26 \pm 5.86$ weeks (18 - 36), were recruited at the end. All the participants had singleton pregnancies. Gestational age was confirmed and determined with routine first-trimester US. Normality of fetuses was confirmed by a minimum of one year postpartum follow-up. The study protocol was approved by the local institutional review board and informed consent was waived by the institutional ethics committee. MRI was performed within 10 days of the ultrasound.

\subsection{MRI}

A 1.5 T Siemens Avanto scanner with a 4-channel body coil was used for all MRIs.

Sequences including T2 half-Fourier acquisition singleshot turbo spin-echo (HASTE) images were obtained with 46.5-mm-thick slices in the axial planes to the fetus's lung. A single radiologist with 7 years' experience in fetal imaging investigated the existing images for possible abnormality meeting the exclusion criteria.

T2-weighted images were obtained by using T2W HASTE images, half-fourier acquisition single-shot turbo spin echo images with a matrix of $256 \times 160-256$. A minimal bandwidth was used for all sequences. The acquisition time was 15 - 30 seconds. Section thickness and intersection gap were 4 - $6.5 \mathrm{~mm}$ and 4.4 - $14.4 \mathrm{~mm}$, respectively. T2weighted images were acquired in transverse planes with respect to the fetal thorax. In the presence of fetal anomalies, additional MR imaging of the fetus in a transverse, coronal and axial plane was performed. If a particular sequence had too much motion, then it was not used for the review.

\subsection{Variables}

One reader selected images acquired with HASTE sequences that contained the complete fields of both lungs without motion artifacts. The cross-sectional area of the lung was measured on each transverse section by manual tracing (Figure 2). The hila of the lung, mediastinum and heart were excluded from lung volume measurement. Fetal lung volume (FLV) measurements were performed twice on separate episodes without knowledge of prior measurements. Average of the two separate measurements was considered the lung volume.

To calculate the volume for each section, we multiplied the value of the sums of cross-sectional areas of different slices by the sum of the section thickness and intersection gap.

\subsection{Statistical Analysis}

Statistical analyses were performed using SPSS software (Statistical Package for the Social Sciences, version 10.5; Chicago, Ill). Mean total fetal lung volume, median, standard deviation (SD), minimum, and maximum were calculated for each gestational week. Afterwards, a onesample $t$-test was done to compare the mean total fetal lung volume at each gestational week with the expected mean total fetal lung volume predicted by the formula by Rypens et al. (16), Meyers et al. (17), and Osada et al. (9). P value was considered statistically significant for values less than 0.05 . To acquire a best-fit formula for the mean total fetal lung volume based on each gestational week with 95\% $\mathrm{CI}$, we used the regression model applied by Rypens et al. (16).

\section{Results}

Total lung volume ranged from 3.82 to $109.5 \mathrm{~mL}$ from 18 to 36 weeks GA (Table 1 ). The relationship between the 


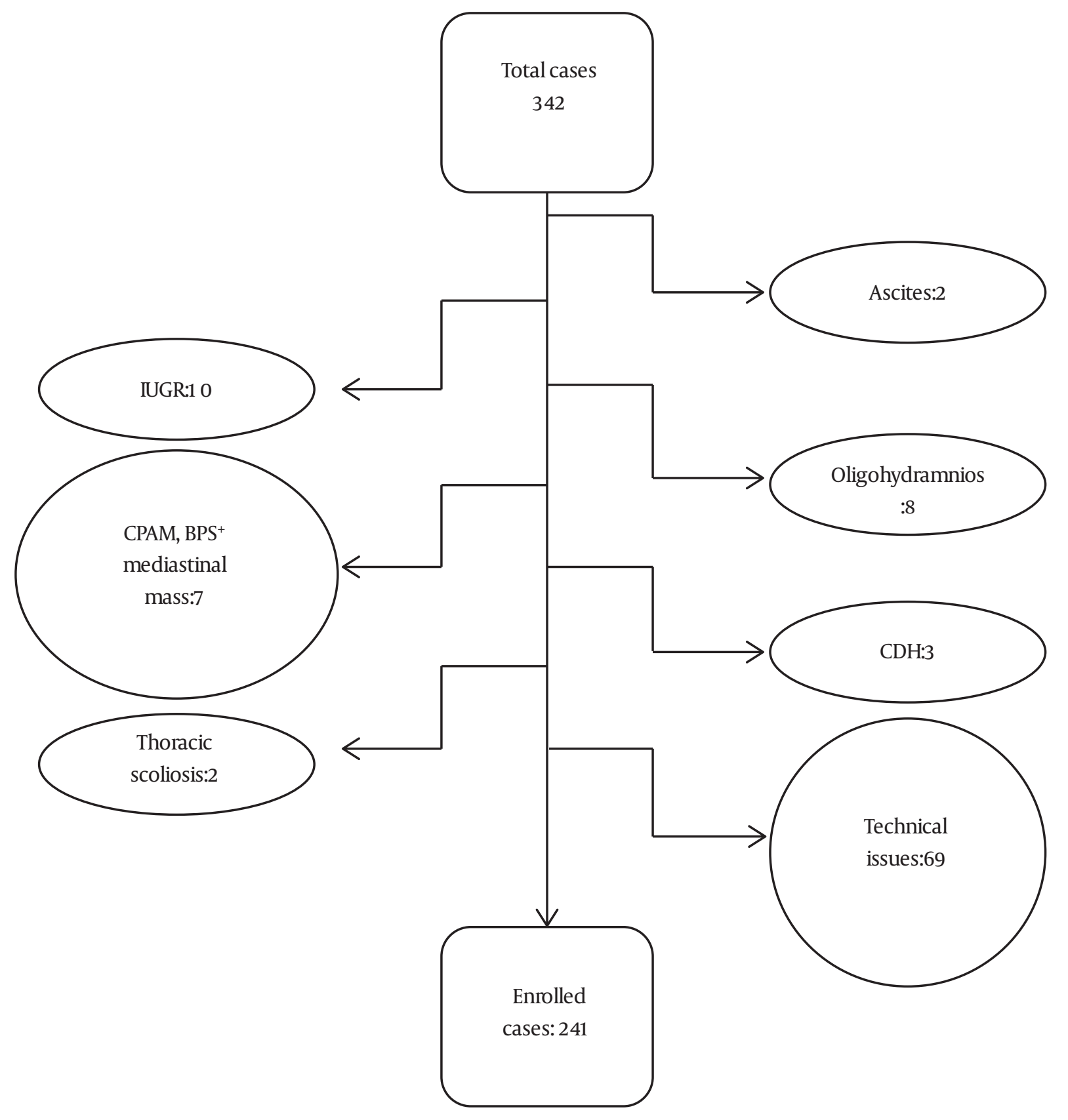

Figure 1. Flow chart illustrates study selection based on the exclusion criteria (Abbreviations: BPS, bronchopulmonary sequestration; CDH, congenital diaphragmatic hernia; CPAM, congenital pulmonary airway malformation; IUGR, intrauterine growth retardation).

total lung volume and gestational age is shown in Figure 2 The best fit for the lung volume was the regression line represented by the equation $\mathrm{V}=0.002 \times\left(\mathrm{GA}^{2.913}\right)$, in which $V$ is the lung volume and GA is the gestational weeks.

FLV increased with gestational age, as illustrated in the Figures 3 and 4, from 18 weeks of GA to 36 weeks, but not with a linear distribution. A decrease in the mean total fetal lung volume from 27 to 28 weeks and 35 to 36 weeks was noted. The later one was also reported in Meyers et al. (17).

Based on Table 2, comparing the mean total fetal lung volume with the expected total fetal lung volume for each gestational age week by the Osada et al. (9), we found 

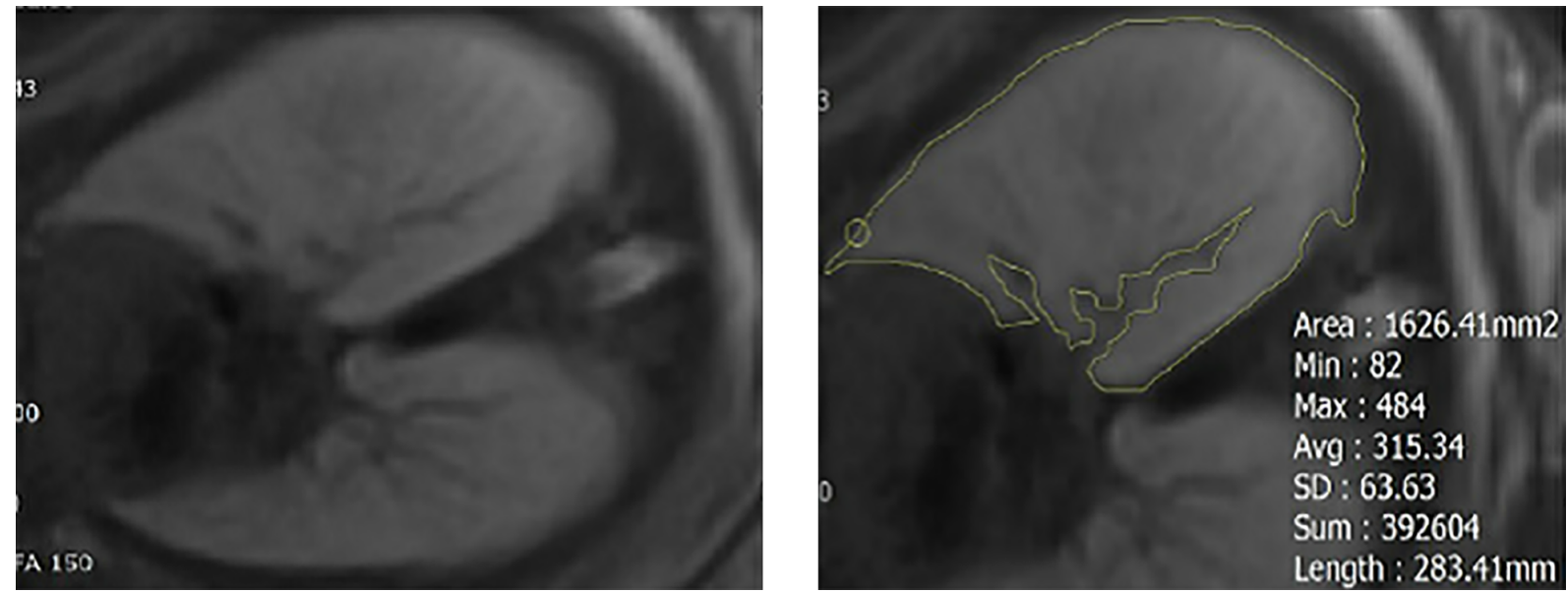

Figure 2. Fetal MRI demonstrating appropriate measurement of lung in the cross-sectional plane

Table 1. Lung Volume (LV) Based on Gestational Age (GA)

\begin{tabular}{|c|c|c|c|c|c|c|}
\hline GA & Mean LV & Number & Standard deviation & Median & Minimum & Maximum \\
\hline 18.00 & 6.8382 & 9 & 1.97930 & 6.5611 & 3.82 & 9.97 \\
\hline 19.00 & 9.5792 & 24 & 3.04680 & 9.0430 & 5.52 & 19.12 \\
\hline 20.00 & 11.1818 & 28 & 2.53224 & 10.6112 & 7.54 & 17.33 \\
\hline 21.00 & 12.4675 & 17 & 2.08773 & 12.5720 & 8.25 & 17.07 \\
\hline 22.00 & 15.0990 & 10 & 4.20479 & 14.9434 & 9.21 & 22.85 \\
\hline 23.00 & 16.7634 & 11 & 2.51566 & 17.1626 & 12.59 & 20.88 \\
\hline 24.00 & 21.2190 & 11 & 4.20695 & 20.1747 & 15.11 & 31.12 \\
\hline 25.00 & 21.6821 & 13 & 1.80661 & 22.5837 & 18.38 & 23.61 \\
\hline 26.00 & 29.4592 & 9 & 5.46292 & 29.4306 & 22.29 & 37.13 \\
\hline 27.00 & 34.9165 & 5 & 4.98786 & 35.4412 & 26.92 & 40.53 \\
\hline 28.00 & 28.1973 & 9 & 7.03799 & 27.6728 & 16.76 & 35.97 \\
\hline 29.00 & 37.0923 & 10 & 10.54665 & 36.9234 & 20.62 & 51.69 \\
\hline 30.00 & 38.9204 & 9 & 10.42489 & 41.5136 & 26.24 & 59.55 \\
\hline 31.00 & 40.5029 & 11 & 12.34308 & 40.3449 & 18.94 & 62.59 \\
\hline 32.00 & 43.3220 & 19 & 8.16032 & 42.4672 & 31.24 & 62.91 \\
\hline 33.00 & 47.7547 & 14 & 9.24501 & 51.6251 & 30.32 & 58.27 \\
\hline 34.00 & 56.7422 & 7 & 24.78870 & 52.4480 & 36.32 & 109.50 \\
\hline 35.00 & 58.2047 & 9 & 11.89166 & 57.4312 & 43.44 & 79.48 \\
\hline 36.00 & 52.8723 & 11 & 13.98617 & 52.8900 & 32.53 & 76.03 \\
\hline Total & 27.6343 & 236 & 18.09921 & 22.3696 & 3.82 & 109.50 \\
\hline
\end{tabular}

that our data distribution resembled those of Osada et al. (9) at every gestational age week except for weeks 19, 26, 27, 33, and 35. The differences between the two data sets were not statistically significant, except for the mentioned weeks. Comparison of our data with those of the studies conducted by Rypens et al. (16) and Meyers et al. (17) revealed a noticeable difference in the acquired lung volume except for week 26, and 27 [compared to Rypens et al. (16)] and 27 [compared to Meyers et al. (17)]. 


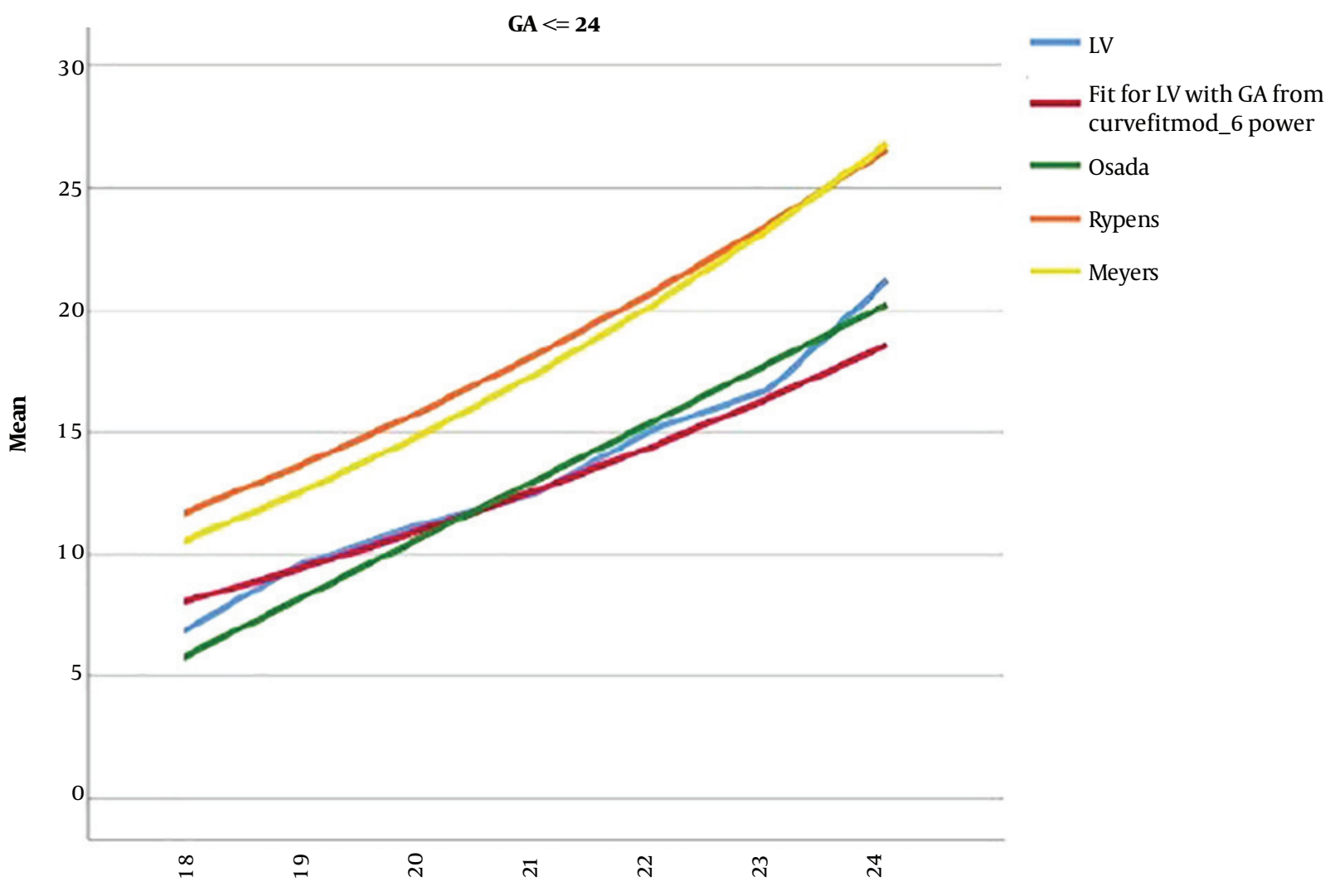

GA

Figure 3. Comparison of normal fetal lung volume at different gestational ages (GA $\leq 24 \mathrm{w}$ ). The blue line is indicating the raw data of acquired lung volume in the fetuses. By means of the regression model applied by Rypens et al. (16), a best-fit formula for the mean total fetal lung volume based on each gestational week with $95 \% \mathrm{CI}$ (shown by the red line) was achieved.

\section{Discussion}

One of the main predictors of respiratory function in the newborn is presence of an adequate area of the gasexchanging epithelium. This surface area is directly correlated with fetal lung volume. Therefore, it is rational to evaluate the fetal lung volumes in the uterus with the purpose of detection of hypoplastic lungs (18).

Pulmonary hypoplasia is associated with a high rate of neonatal morbidity and mortality. For selected causes of pulmonary hypoplasia, prenatal intervention is available. For all prognoses, management and follow-up schedules depend on the degree of hypoplasia and volume of the remaining lung tissue. Thus, such fetuses could benefit from antenatal detection of restricted pulmonary development. In order to call a lung small-sized or underdeveloped, comparison with a valid, population based, normal reference value is necessary.
Since the 1980s (19), fetal MR has been used as a competent, non-invasive, and harmless modality to study fetal lung development after 18 gestational weeks (GW) in the uterus. In addition to the prior role of MRI in the evaluation of lung growth, the high resolution and tissue contrast of MRI allows us to study the structure of the fetal lung and more detailed fetal pulmonary pathologies. So far, few studies have applied fetal MR lung volumetry to evaluate the lung volume of normal fetuses $(12,20)$ to establish a reference data for detection of fetuses with abnormally small lungs $(9,21)$.

Fetal MRI is typically performed due to abnormal results found at anatomical surveys generally performed around 18 weeks of gestation. Before 18 weeks of gestation, because of the limitations in spatial resolution and difficulty in the diagnosis of anomalies including congenital diaphragmatic hernia (CDH), fetal MRI is hardly used. Al- 


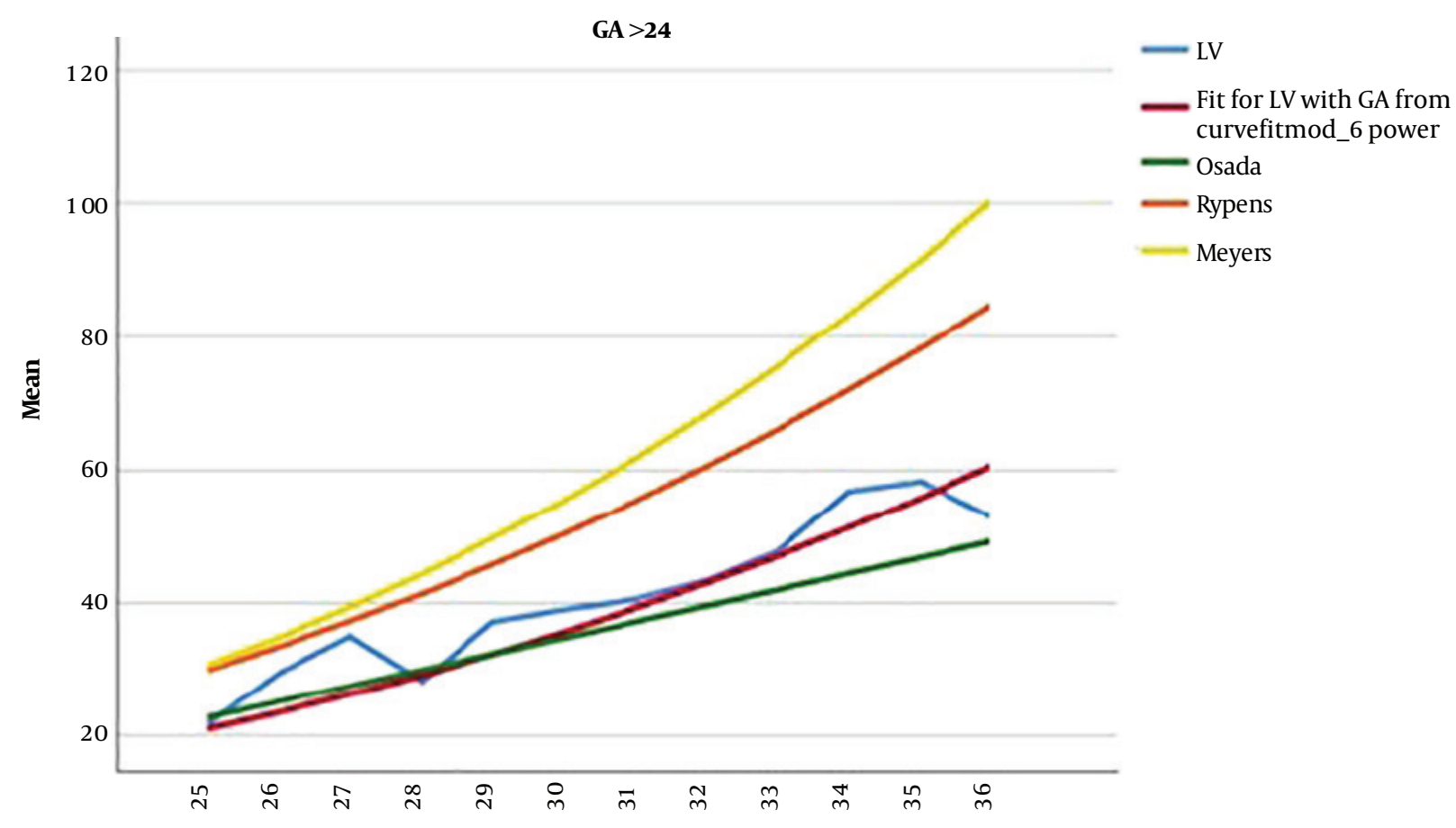

GA

Figure 4. Comparison of normal fetal lung volume at different gestational ages (GA> $24 \mathrm{w}$ ). The blue line is indicating the raw data of acquired lung volume in the fetuses. By means of the regression model applied by Rypens et al. (16), a best-fit formula for the mean total fetal lung volume based on each gestational week with $95 \% \mathrm{CI}$ (shown by the red line) was achieved.

though fetal MRI becomes increasingly more accurate in the later gestational ages, restrictions imposed by age of legal abortion in most countries necessitate earlier diagnosis. However, in most studies of normal fetal lung volumesthis early period ( 18 - 22 weeks GA) is under-represented despite its significance $(13,16)$.

Our study complements previous research of the volumetric assessment of fetal lung growth.

There is high inconsistency in total lung volumes as reported by different investigators. In the lack of universally accepted standardized values, this wide range of data generates the likelihood of overlap between normal and abnormal fetal lung volume values.

Rypens et al. (16) estimated FLV at 21-38 weeks gestation in 215 fetuses without thoracoabdominal malformations and with normal US biometric findings (range, 16 - $150 \mathrm{~mL}$ ) increased with gestational age. However, Meyers et al. (17) showed that the measured mean total fetal lung volume values at 19 - 22 weeks were significantly lower than those predicted by the Rypens formula. Although the obtained volumes in our study were lower than the data of men- tioned studies at every gestational week, the differences are much noticeable at older gestational age which could be due to biologic variation. This will enhance the possibility of overlap with hypoplastic lung volumes in late pregnancy. At 19 - 22 weeks, our results were more similar to those of Meyers et al. (17) than Rypens et al. (16) There was a higher number of measurements made in this gestational age range in our study and the study performed by Meyers et al. (17) compared to the study conducted by Rypens et al. (16). Our data in this time period was closer to Meyers dataset. Meanwhile, our data set later in pregnancy was significantly lower than both studies. This difference between our study and the two mentioned studies could be related to many factors including the different ethnicities, and different measurement techniques.

On the other hand, several studies have also stated race-based variances in gestational age-specific birth weights. Wang et al. (22) showed that the gestational age-specific mean birth weights of white American babies were higher than those of Japanese babies. The mentioned relationship could be extended to the lung volume, con- 


\begin{tabular}{|c|c|c|c|c|c|c|c|}
\hline GA & Mean & Rypens et al. (16) & Pvalue & Meyers et al. (17) & Pvalue & Osada et al. (9) & Pvalue \\
\hline 18.00 & 6.8382 & 11.6735 & 0.000 & 10.5117 & 0.001 & 5.7800 & 0.147 \\
\hline 19.00 & 9.5792 & 13.6256 & 0.000 & 12.5337 & 0.000 & 8.1900 & 0.036 \\
\hline 20.00 & 11.1818 & 15.7785 & 0.000 & 14.8104 & 0.000 & 10.6000 & 0.235 \\
\hline 21.00 & 12.4675 & 18.1413 & 0.000 & 17.3587 & 0.000 & 13.0100 & 0.300 \\
\hline 22.00 & 15.0990 & 20.7229 & 0.002 & 20.1957 & 0.004 & 15.4200 & 0.815 \\
\hline 23.00 & 16.7634 & 23.5322 & 0.000 & 23.3388 & 0.000 & 17.8300 & 0.190 \\
\hline 24.00 & 21.2190 & 26.5782 & 0.002 & 26.8055 & 0.001 & 20.2400 & 0.458 \\
\hline 25.00 & 21.6821 & 29.8696 & 0.000 & 30.6135 & 0.000 & 22.6500 & 0.077 \\
\hline 26.00 & 29.4592 & 33.4153 & 0.061 & 34.7808 & 0.019 & 25.0600 & 0.042 \\
\hline 27.00 & 34.9165 & 37.2239 & 0.360 & 39.3255 & 0.120 & 27.4700 & 0.029 \\
\hline 28.00 & 28.1973 & 41.3041 & 0.001 & 44.2658 & 0.000 & 29.8800 & 0.494 \\
\hline 29.00 & 37.0923 & 45.6646 & 0.030 & 49.6203 & 0.005 & 32.2900 & 0.184 \\
\hline 30.00 & 38.9204 & 50.3139 & 0.011 & 55.4075 & 0.001 & 34.7000 & 0.259 \\
\hline 31.00 & 40.5029 & 55.2606 & 0.003 & 61.6463 & 0.000 & 37.1100 & 0.383 \\
\hline 32.00 & 43.3220 & 60.5132 & 0.000 & 68.3556 & 0.000 & 39.5200 & 0.057 \\
\hline 33.00 & 47.7547 & 66.0802 & 0.000 & 75.5545 & 0.000 & 41.9300 & 0.035 \\
\hline 34.00 & 56.7422 & 71.9699 & 0.155 & 83.2623 & 0.030 & 44.3400 & 0.234 \\
\hline 35.00 & 58.2047 & 78.1908 & 0.001 & 91.4984 & 0.000 & 46.7500 & 0.020 \\
\hline 36.00 & 52.8723 & 84.7513 & 0.000 & 100.2823 & 0.000 & 49.1600 & 0.399 \\
\hline
\end{tabular}

Abbreviations: GA, gestational age.

${ }^{\text {a }}$ P value $<0.05$ is significant.

sidering the different results of studies for estimation of the normal lung volume in each country. As described before, our result showed the most similarity to the study conducted by Osada et al. (9) which owned the closest match to the race of our population compared to European and American populations in a study performed by Rypens et al. (16) and Meyers et al. (17), respectively. Therefore, it could be concluded that offering a single worldwide practical data base for fetal lung volume is not rational.

As one of the limitations of our study, it should be mentioned that sampling was not performed among a strictly healthy population and it may involve fetuses with structural abnormalities outside the chest cavity referred for prenatal MR imaging. However, this selection limitation was minimized by excluding the fetuses with thoracic abnormalities and other intervening factors, and the measurements obtained in the subjects of the study represent rational estimates of normal lung development.

Second, lung volume measurements may alter with the cardiac cycle or fetal breathing. In this study, such effect tried to be degraded via the acquisition time and by multiple measurements and obtaining a mean fetal lung volume. Third, two plane measurement and 3-D volumetry were not accessible for comparison.

In conclusion, the lung volume can be predicted with a high degree of accuracy in fetuses with the same biological alterations through each gestational age by developing prenatal MR imaging lung volumetry to avoid and prepare for neonatal respiratory problems which are responsible for a high rate of mortality and morbidity.

\section{Footnotes}

Authors' Contributions: All the authors participated in the mentioned stages below: substantial contributions to the conception or design of the work, or the acquisition, analysis or interpretation of data, drafting the work or revising it critically for important intellectual content, final approval of the version published, and agreement to be accountable for all aspects of the work in ensuring that questions related to the accuracy or integrity of any part of the work are appropriately investigated and resolved.

Conflict of Interests: There was no financial interests related to the material in the manuscript. 
Ethical Approval: $\quad$ Ethical code: IR.SUMS.REC.1397.1018 (http://research.sums.ac.ir/fa/ethicrc/EthicsCodes.html).

Funding/Support: This study was from the thesis of the degree of specialty in radiology (project no. 97-01-48-18687) of Amin Dehdashtian and supported by Shiraz University of medical sciences, Shiraz, Iran.

Informed Consent: Since this was a retrospective study and MRI images were obtained for diagnostic reasons before beginning of the study and not for research purposes, informed consent was waived by the Institutional Ethics Committee. No harm neither (to the fetus nor to the mother) or extra charges was made to the subjects during reviewing the MR images.

\section{References}

1. Sohaey R, Zwiebel WJ. The fetal thorax: Noncardiac chest anomalies. Semin Ultrasound CT MR. 1996;17(1):34-50. doi: 10.1016/s08872171(96)90043-8.

2. Sherer DM, Davis JM, Woods JJ. Pulmonary hypoplasia: A review. Obstet Gynecol Surv. 1990;45(11):792-803. doi: 10.1097/00006254-19901100000026. [PubMed: 2234705].

3. Guibaud L, Filiatrault D, Garel L, Grignon A, Dubois J, Miron MC et al. Fetal congenital diaphragmatic hernia: Accuracy of sonography in the diagnosis and prediction of the outcome after birth. AJR Am J Roentgenol. 1996;166(5):1195-202. doi: 10.2214/ajr.166.5.8615269. [PubMed: 8615269].

4. Metkus AP, Filly RA, Stringer MD, Harrison MR, Adzick NS. Sonographic predictors of survival in fetal diaphragmatic hernia. $J$ Pediatr Surg. 1996;31(1):148-51. discussion 151-2. doi: 10.1016/s00223468(96)90338-3. [PubMed: 8632269].

5. Johnson IR, Stehling MK, Blamire AM, Coxon RJ, Howseman AM, Chapman B, et al. Study of internal structure of the human fetus in utero by echo-planar magnetic resonance imaging. Am J Obstet Gynecol.1990;163(2):601-7. doi:10.1016/0002-9378(90)91209-u. [PubMed: 2386150].

6. Kiefer B. Image acquisition in a second with half-Fourier-acquisition single-shot turbo spin echo. J Magn Reson Imaging. 1994;4:86.

7. Levine D, Barnes PD, Sher S, Semelka RC, Li W, McArdle CR, et al. Fetal fast MR imaging: Reproducibility, technical quality, and conspicuity of anatomy. Radiology. 1998;206(2):549-54. doi: 10.1148/radiology.206.2.9457211. [PubMed: 9457211].

8. Coakley FV, Hricak H, Filly RA, Barkovich AJ, Harrison MR. Complex fetal disorders: Effect of MR imaging on management-preliminary clinical experience. Radiology. 1999;213(3):691-6. doi: 10.1148/radiology.213.3.r99dc39691. [PubMed: 10580940].
9. Osada H, Kaku K, Masuda K, Iitsuka Y, Seki K, Sekiya S. Quantitative and qualitative evaluations of fetal lung with MR imaging. Radiology. 2004;231(3):887-92. doi:10.1148/radiol.2313021689. [PubMed:15118120]

10. Duncan KR, Gowland PA, Moore RJ, Baker PN, Johnson IR. Assessment of fetal lung growth in utero with echo-planar MR imaging. Radiology. 1999;210(1):197-200. doi: 10.1148/radiology.210.1.r99ja42197. [PubMed: 9885608].

11. Ward VL, Nishino M, Hatabu H, Estroff JA, Barnewolt CE, Feldman HA, et al. Fetal lung volume measurements: Determination with MR imaging-effect of various factors. Radiology. 2006;240(1):187-93. doi: 10.1148/radiol.2393050583. [PubMed: 16793978].

12. Keller TM, Rake A, Michel SC, Seifert B, Wisser J, Marincek B, et al. MR assessment of fetal lung development using lung volumes and signal intensities. Eur Radiol.2004;14(6):984-9. doi:10.1007/s00330-0042256-x. [PubMed: 15014973].

13. Kasprian G, Balassy C, Brugger PC, Prayer D. MRI of normal and pathological fetal lung development. Eur J Radiol. 2006;57(2):261-70. doi: 10.1016/j.ejrad.2005.11.031. [PubMed: 16413987].

14. Jani J, Breysem L, Maes F, Boulvain M, Roubliova X, Lewi L, et al. Accuracy of magnetic resonance imaging for measuring fetal sheep lungs and other organs. Ultrasound Obstet Gynecol. 2005;25(3):270-6. doi 10.1002/uog.1866. [PubMed: 15736207].

15. Walsh DS, Hubbard AM, Olutoye OO, Howell LJ, Crombleholme $\mathrm{TM}$, Flake AW, et al. Assessment of fetal lung volumes and liver herniation with magnetic resonance imaging in congenital diaphragmatic hernia. Am J Obstet Gynecol. 2000;183(5):1067-9. doi: 10.1067/mob.2000.108895. [PubMed: 11084542].

16. Rypens F, Metens T, Rocourt N, Sonigo P, Brunelle F, Quere MP, et al. Fetal lung volume: Estimation at MR imaging-initial results. Radiology. 2001;219(1):236-41. doi: 10.1148/radiology.219.1.r01ap18236. [PubMed: 11274563].

17. Meyers ML, Garcia JR, Blough KL, Zhang W, Cassady CI, MehollinRay AR. Fetal lung volumes by MRI: Normal weekly values from 18 through 38 weeks' gestation. AJR Am J Roentgenol. 2018;211(2):432-8. doi: 10.2214/AJR.17.19469. [PubMed: 29894217].

18. Langston C, Kida K, Reed M, Thurlbeck WM. Human lung growth in late gestation and in the neonate. Am Rev Respir Dis. 1984;129(4):60713. [PubMed: 6538770].

19. Smith FW, Adam AH, Phillips WD. NMR imaging in pregnancy. Lancet 1983;1(8314-5):61-2. doi: 10.1016/s0140-6736(83)91588-x. [PubMed: 6129387].

20. Williams G, Coakley FV, Qayyum A, Farmer DL, Joe BN, Filly RA. Fetal relative lung volume: Quantification by using prenatal MR imaging lung volumetry. Radiology. 2004;233(2):457-62. doi: 10.1148/radiol.2332031566. [PubMed: 15459321]

21. Tanigaki S, Miyakoshi K, Tanaka M, Hattori Y, Matsumoto T, Ueno K, et al. Pulmonary hypoplasia: Prediction with use of ratio of MR imagingmeasured fetal lung volume to US-estimated fetal body weight. Radiology. 2004;232(3):767-72. doi: 10.1148/radiol.2323030359. [PubMed: 15333796].

22. Wang X, Guyer B, Paige DM. Differences in gestational age-specific birthweight among Chinese, Japanese and white Americans. Int J Epidemiol. 1994;23(1):119-28. doi: 10.1093/ije/23.1.119. [PubMed: 8194906]. 